\title{
Experimental characterization of the unsteady perfor- mance behavior of a Wells turbine operating at high flow rate coefficients
}

\author{
Marco Torresi ${ }^{1, *}$, Michele Stefanizzi ${ }^{1}$, Luana Gurnari $^{2}$, Pasquale G. F. Filianoti ${ }^{2}$, and Sergio \\ M. Camporeale ${ }^{1}$ \\ ${ }^{1}$ Department of Mechanics, Mathematics and Management, Polytechnic University of Bari, 70125 Bari, \\ Italy \\ ${ }^{2}$ Department of Civil, Energy, Environment and Materials Engineering, Mediterranean University of \\ Reggio Calabria, 89124 Reggio Calabria, Italy
}

\begin{abstract}
Even if researchers are working on the exploitation of marine energy for more than thirty years, blue energy is not yet a consolidated reality and still contributes marginally to the world energy mix. For this reason, in the last years, the effort of the scientific community has been significantly intensified to further improve the know-how on marine energy harvesting. The goal is to allow ocean energy to effectively contribute to a more sustainable energy production in the next future. In the wide range of technologies for wave energy harvesting, Oscillating Water Column (OWC) devices are counted among of the most mature ones. Due to the oscillating nature of the generated air flow, which continuously inverts its direction, OWC devices need to be coupled with self-rectifying turbines, such as Wells, impulse, or biradial turbines. Wells turbines can reach high efficiencies, but their performance can show a hysteretic behaviour due to dynamic stall phenomena, especially in presence of high amplitude flow rate oscillations. Moreover, under dynamic stall conditions, during the flow deceleration, the shaft torque evidence the presence of gradually damped fluctuations, which delay the flow reattachment, superposed to the hysteresys loop. In order to better characterize this phenomenon, a new experimental campaign was performed in the open wind tunnel of the Polytechnic University of Bari on a 3D-printed Wells turbine model. The interest is mainly focused on the dependency of these torque fluctuations on the amplitude and frequency of the oscillating flow.
\end{abstract}

\section{Introduction}

The gap between ambition and reality in tackling climate change remains as wide as ever, despite climate change negative effects are becoming year by year more catastrophic. Yet global energy-related $\mathrm{CO}_{2}$ emissions have risen by $1 \%$ per year on average over the last decade [1]. In this scenario, the International Renewable Energy Agency (IRENA) highlights the need of an appropriate long-term socio-economic development, aimed at improving people's welfare. Indeed, the future socio-economic situation will need of an appropriate new energy scenario,

\footnotetext{
*e-mail: marco.torresi@poliba.it
} 
able to satisfy every necessity. For this reason, this path can be tracked only by persevering in the transition toward a decarbonization of the energy production by means of renewable sources. For example, the IRENA's outlook suggests a 70\% cut of the world's energy-related carbon $\mathrm{CO}_{2}$ emissions by 2050 .

Among renewable energies, the marine energy sector represents one of the greatest technological challenges and the one with the highest growth potential. Even if researchers are working on the exploitation of marine energy for more than thirty years, blue energy is not yet a consolidated reality in the world energy mix. For this reason, in the last years, the effort of the scientific community has been significantly intensified to further improve the know-how on the marine energy. The goal is to allow ocean energy resources to effectively contribute to a more sustainable energy production in the next future. The global gross theoretical wave potential can be evaluated in $3.7 \mathrm{TW}$; whereas the net available power (excluding both potentially ice-covered areas and areas where the power is lower than $5 \mathrm{~kW} / \mathrm{m}$ ) reduces to $3.0 \mathrm{TW}$ [2], but the current total installed capacity amounts to only 530.6 MW [3]. Obviously, not all sites are suitable for marine energy harvesting. The common issue found in the use of this technology is due to the unpredictability of extreme events that can lead to irreversible damage of coastal structures and their devices $[4,5]$. The predisposition to the exploitation of the wave motion varies therefore from country to country and strongly depends on the temporal variability of the energy available from the wave motion. Moreover, the marine energy essentially depends on wind speed and its duration, water depth, seabed conditions and interaction with other waves.

Among the wide range of technologies, Oscillating Water Column (OWC) devices can be count among the most mature ones for wave energy harvesting. Due to the oscillating nature of the generated air flow direction and the continuous change in its speed, OWC devices need to be coupled with self-rectifying turbines, for instance Wells turbines [6]. This kind of turbine can reach high efficiencies, but its performance can show a hysteretic behaviour due to dynamic stall phenomena, especially when high flow rates are reached [7]. During the experimental campaign of a Wells turbine prototype, high frequency gradually damped fluctuations of torque have been evidenced under dynamic stall conditions. The interest of this work has been mainly focused on the influence of the amplitude and frequency of the main flow oscillation on the characteristics of these high frequency torque fluctuations.

\section{The Wells Turbine}

The peculiar characteristic of the Wells turbine consists in its capacity to rotate in the same way regardless of the air flow direction. This is due to its symmetrical airfoils, staggered at a 90 deg angle. A Wells turbine can work at high rotational speed allowing the direct coupling with electrical generators. In addition, thanks to the fly-wheel effect, the turbine involves an important energy storage, simplifying a constant speed control [8].

As depicted in Figure 1, a Wells turbine blade is subjected to a lift force, $L$, and a drag force, $D$, which are respectively orthogonal and parallel to the relative air flow velocity, $W_{\infty}$. These two forces can be resolved into the tangential, $F_{u}$, and the axial, $F_{n}$, components, whose magnitudes periodically change during air flow variations. Looking at Figure 1, it is possible to notice how the flow direction does not affect the direction of the tangential force. $F_{u}$ will be negative whenever the drag becomes dominant, i.e., either when the flow rate approaches to zero or when stall conditions occur [9].

Figure 2 shows the 3D-printed prototype of the Wells turbine under investigation. The turbine has been designed and preliminary tested in a previous work [10], where all the detailed technical and geometric information can be found. However, Table 1 summarizes the main parameters of the rotor. 


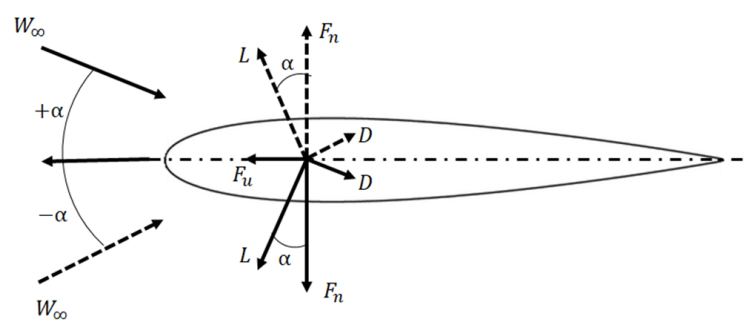

Figure 1. Forces acting on a typical Wells turbine blade.

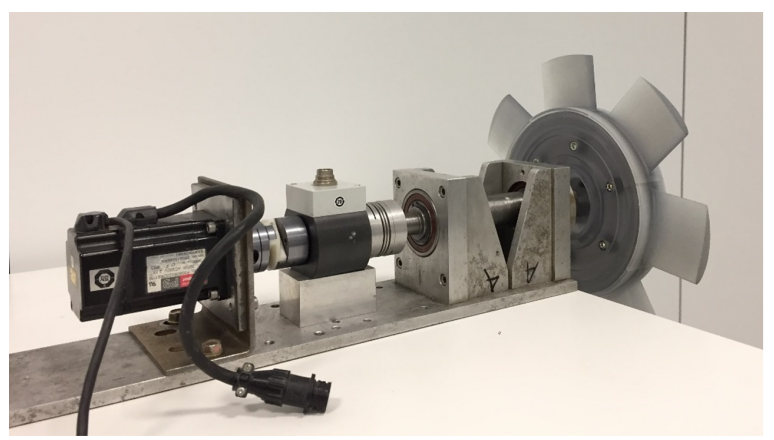

(a)

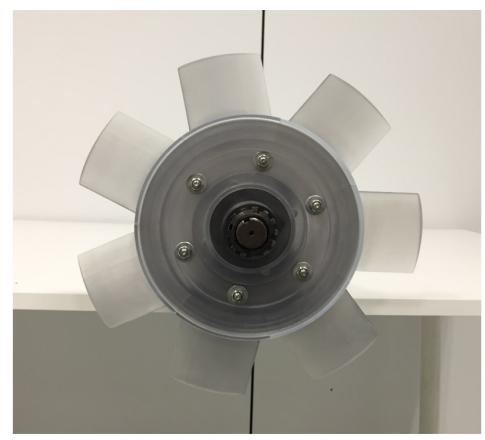

(b)

Figure 2. The small-scale model of the 3D-printed Wells turbine (a); Assembly view of the rotor (b).

Table 1. Main geometric parameters of the Wells turbine.

\begin{tabular}{lll}
\hline Parameters & Values & Units \\
\hline$R_{\text {hub }}$ & 100 & $\mathrm{~mm}$ \\
$R_{\text {tip }}$ & 155 & $\mathrm{~mm}$ \\
Blade chord $c$ & 74 & $\mathrm{~mm}$ \\
Number of blades & 7 & - \\
Blade profile & NACA0015 & - \\
\hline
\end{tabular}

The characteristic curves of the Wells turbine are usually given in terms of nondimensional parameters (i.e. $\Delta p^{*}, T^{*}, \eta^{*}$ vs. $U^{*}$ ). In details, $\Delta p^{*}$ represents the stagnation pressure drop coefficient, which is defined according to equation 1 :

$$
\Delta p^{*}=\frac{\Delta p^{0}}{\rho_{a} \omega^{2} R_{t i p}^{5}}
$$

where $\Delta p^{0}$ is the stagnation pressure drop across the turbine, $\omega$ is the angular speed, $R_{t i p}$ is the blade tip radius, $\rho_{a}$ is the air density.

Equation 2 defines the torque coefficient, which depends on the Wells turbine torque, $T_{t}$. 


$$
T^{*}=\frac{T_{t}}{\rho_{a} \omega^{2} R_{t i p}^{5}}
$$

It must be specified that the torque measured by the torque meter, $T_{\text {Torque meter }}$, differs from the one, which is applied by the fluid flow to the blades, $T_{t}$. This can be explained because of the presence of aerodynamic windage (due to air turbulence and shear on the shaft and the turbine hub), mechanical frictions (mainly on bearings) and flywheel effects (here negligible since the control system is able to keep constant the rotational speed). The prototype has been tested at various rotational speeds without flow in order to evaluate the windage and the friction losses. These tests have been carried out by keeping the wind tunnel blower turned off, $T_{\text {Torque meter }}^{(v=0 \mathrm{~m} / \mathrm{H}}$. However, under these flow conditions, one measures the windage and friction losses together with the drag of the turbine blades due to the relative flow having an angle of attack equal to $0 \mathrm{deg}, T_{t}^{(v=0 \mathrm{~m} / \mathrm{s})}$. This drag effect has been derived from 3D CFD simulations performed in previous works by Torresi et al. [11-13]. Finally, the aerodynamic turbine torque, $T_{t}$, can be derived according to equation 3 :

$$
T_{t}=-T_{\text {Torque meter }}+T_{\text {Torque meter }}^{(v=0 \mathrm{~m} / \mathrm{s}}-T_{t}^{(v=0 \mathrm{~m} / \mathrm{s})}
$$

The flow rate across the turbine can be evaluated by means of the flow coefficient $U^{*}$, which is defined as follows:

$$
U^{*}=\frac{V}{\omega R_{t i p}}
$$

where $V=Q / A_{a}$ is the mean axial velocity in the annular section $\left(A_{a}\right)$ upstream the turbine.

Finally, the efficiency is computed by means of equation 5 , i.e., the ratio between the turbine power $P_{t}=\omega T_{t}$ and the available pneumatic power, $P_{p}=Q \Delta p^{0}$, generated by the air flow rate, $Q$.

$$
\eta=\frac{\omega T_{t}}{P_{p}}
$$

\section{The test rig}

The turbine has been tested in an open circuit wind tunnel at the GaVe Lab of the Polytechnic University of Bari (Figure 3). The air is aspirated by a squirrel cage blower installed at the end of the wind tunnel (model A0 112M - 4 by ELPROM), which is driven by an AC electric motor (2 poles, nominal power equal to $4.1 \mathrm{~kW}$ at $1430 \mathrm{rpm}$ ). The electric motor is controlled by a variable frequency vector control drive (Omron V1000).

Then, the air flow enters in the wind tunnel across a $1 \mathrm{~m}$ long convergent pipe, with an inlet diameter equal to $455 \mathrm{~mm}$ and an outlet diameter equal to $314 \mathrm{~mm}$. After leaving the Wells turbine, the flow is directed into the settling chamber $(1.5 \mathrm{~m}$ long, $1.0 \mathrm{~m}$ wide and $1.0 \mathrm{~m}$ high). This chamber is used to eliminate any tangential velocity component by means of a honeycomb.

The flow measurements are performed downstream of the settling chamber, according to the ISO 5147-1 standard. Indeed, orifices of different diameter ratios, $\beta$, have been used as pressure differential devices to reduce uncertainty at the different flow rates (namely $\beta=0.2$, $0.3,0.4,0.5,0.6$ and 0.75$)$. 
The experimental setup is also constituted of a series of electronic measurement devices: a Honeywell 163PC01D36 amplified pressure transducer (pressure range of $\pm 5^{\prime \prime} \mathrm{H}_{2} \mathrm{O}$ - accuracy $\pm 2 \%$ ) measures the relative pressure upstream of the orifice, whereas a Honeywell 164PC01D76 amplified pressure transducer is used to measure the differential pressure value across the same orifice. A second Honeywell 163PC01D36 amplified pressure transducer (pressure range of $0 \div 5^{\prime \prime} \mathrm{H}_{2} \mathrm{O}$ - accuracy $\pm 2 \%$ ) is used to measure the stagnation pressure drop across the machine. Actually, the pressure difference is evaluated by connecting its pressure tap in the settling chamber and leaving the other side open to measure the atmospheric pressure. Moreover, the slight pressure losses at the air duct ends and at the turbine hub have been neglected. A Servo Motor (P-Series by SanyoDenky) is connected to the turbine and used as generator. An HBM T22/5NM torque meter $\left(C_{\max }=5 \mathrm{Nm}\right.$, accuracy class 0.5$)$ is installed to measure the turbine shaft torque.

The whole test rig is remotely controlled by means of an in-house software implemented in the NI LabVIEW ${ }^{\circledR}$ environment. Furthermore, since the calculation of the mass flow rate requires an iterative procedure, as specified in the ISO 51447-1, the acquired data are postprocessed by means of a code written in MATLAB ${ }^{\circledR}$.

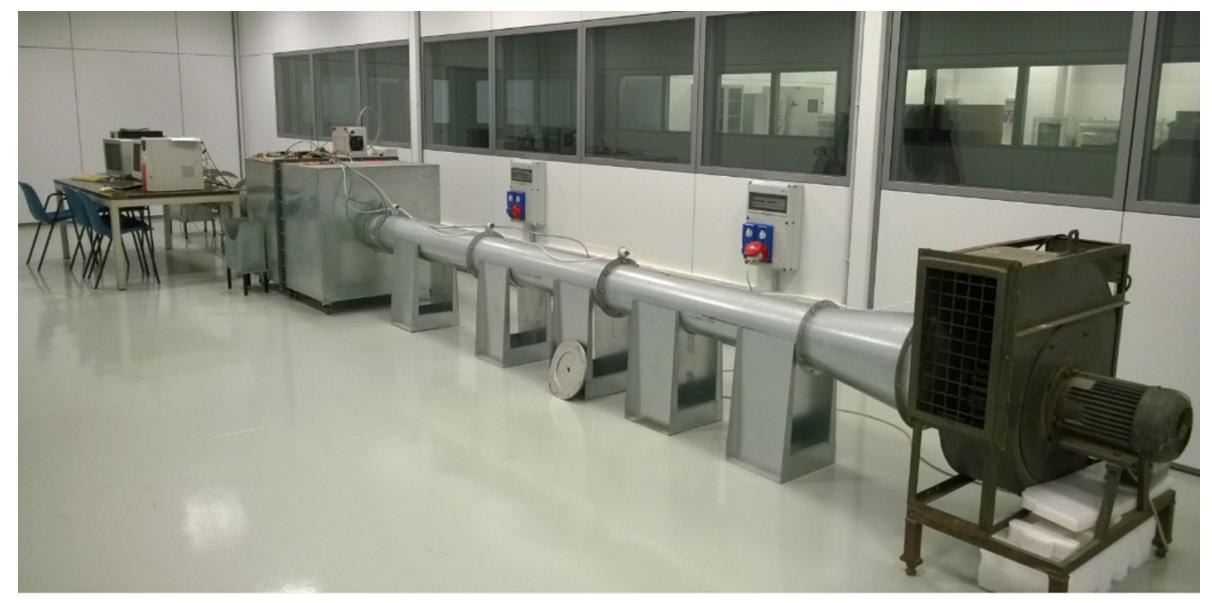

Figure 3. View of the open circuit wind tunnel used for the experimental tests of the smallscale Wells turbine.

\section{Experimental characterization}

The experimental campaign has been designed with the aim to investigate the behaviour of the Wells turbine under unsteady flow conditions and its dependency on the amplitude and frequency of the flow variation. In particular, the turbine has been tested at a constant rotational speed, $n=1750 \mathrm{rpm}$, with an orifice having a diameter ratio $\beta=0.6$. In order to simulate the oscillating flow working conditions, the frequency of the vector control drive, $f$, has been varied cyclically (30 cycles), as shown in Equation 6:

$$
f(t)=\bar{f}+\Delta f \sin (2 \pi t / T)
$$

The sinusoidal oscillation of the frequency determines the same oscillation of both the rotational speed of the blower and the flow rate.

As summarized in the scheme of Figure 4, several tests have been carried out by selecting three values of the period, $T$, equal to $10 s, 15 s$ and $20 s$. For each period, two values of the 
mean frequency have been selected ( $\bar{f}$ equal to $20 \mathrm{~Hz}$ and $35 \mathrm{~Hz}$ ). Finally, for each couple of $T$ and $\bar{f}$, three values of frequency amplitude have been considered ( $\Delta f$ equal to $5 \mathrm{~Hz}, 10 \mathrm{~Hz}$ and $15 \mathrm{~Hz}$ ). Therefore, a total of 18 tests have been performed in this work.

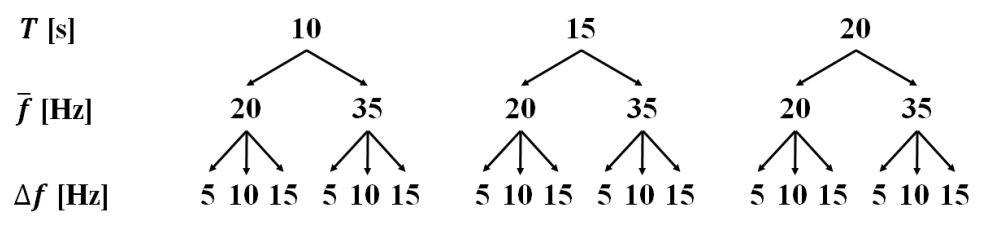

Figure 4. Different experimental tests scheme.

Figure 5 compares the time evolution of the mass flow rate for three out of eighteen tests. Specifically, the tests are characterized by the same mean frequency, $\bar{f}=35 \mathrm{~Hz}$, and frequency amplitude, $\Delta f=15 \mathrm{~Hz}$, but different periods. The behaviour at $T=10 \mathrm{~s}$ shows a marked difference with respect those at $T=15 \mathrm{~s}$ and $T=20 \mathrm{~s}$, losing its sinusoidal pattern. This can be caused by the delay between the velocity variation of the intake air and the variation of the flow rate crossing the turbine. For this reason, all the tests with $T=10 \mathrm{~s}$ have been neglected and those with $T=15 \mathrm{~s}$ have been used as reference. Moreover, $T=15 \mathrm{~s}$ is closer to the period of oscillation of the marine waves, typical of the system for which the turbine was designed.

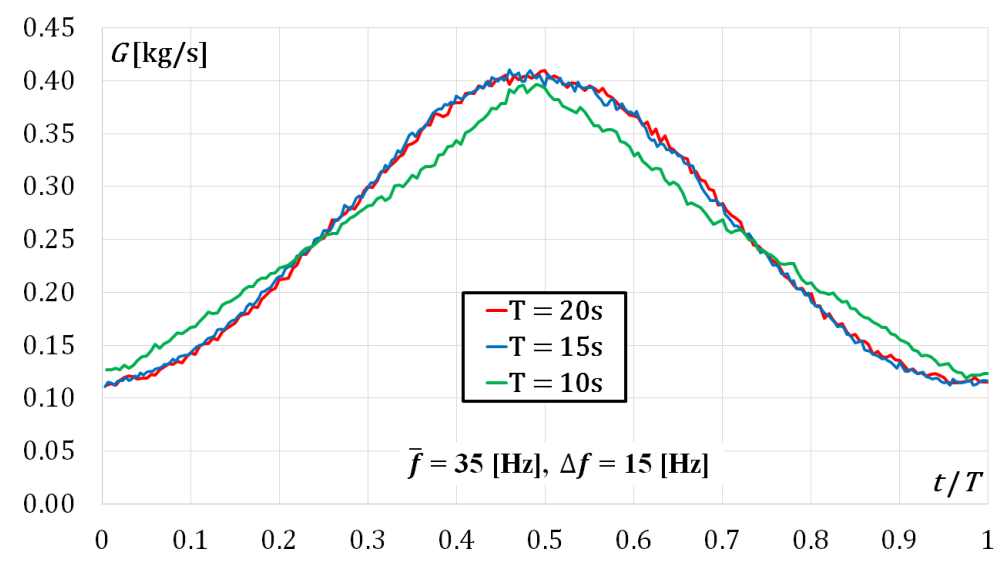

Figure 5. Comparison of mass flow rate trends for different periods of the control drive sinusoidal frequency signal $(\bar{f}=35 \mathrm{~Hz}$, and frequency amplitude, $\Delta f=15 \mathrm{~Hz})$.

Figure 6 highlights the main effect of $\bar{f}$ on the unsteady behaviour of the turbine by comparing the steady state $T^{*}$ curve at $1750 \mathrm{rpm}$ and the unsteady $T^{*}$ curve obtained by changing the frequency signal sent to the control drive. Regarding the steady state curve, it is possible to notice how the torque coefficient, $T^{*}$, becomes positive for $U^{*}>0.07$. This implies that the Wells turbine under investigation is not self-starting. Indeed, for $U^{*}<0.07$ the turbine needs to be driven by the electric motor. Moreover, the torque coefficient, $T^{*}$, increases up to $U^{*}=0.21$, then drastically decreases for higher flow coefficients, due to stall, i.e. the relative air flow is no longer able to follow the blade profile and flow separation occurs. In Figure 6a, the unsteady curve (30 cycles) is related to the test characterized by small flow rates, avoiding any significant flow separation $(T=15 s, \bar{f}=20 \mathrm{~Hz}$ and $\Delta f=15 \mathrm{~Hz})$. Under this flow condition, no hysteresis cycle occurs. This is coherent with the findings of Ghisu 
et al., who proved that the hysteresis in Wells turbines (under low angle of attack) is mainly caused by compressibility effects within the air chamber (i.e. a phase delay between piston speed variation and turbine mass-flow rate variation) and not by an aerodynamic hysteresis of the turbine $[14,15]$.

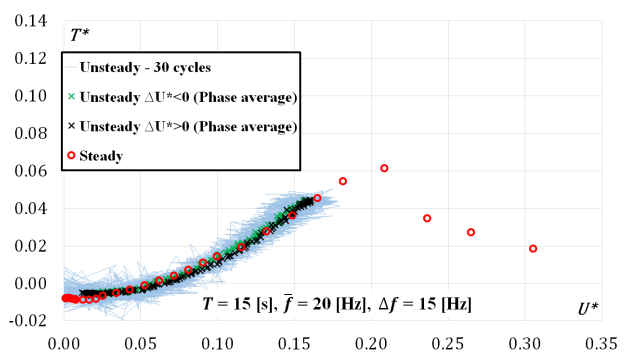

(a)

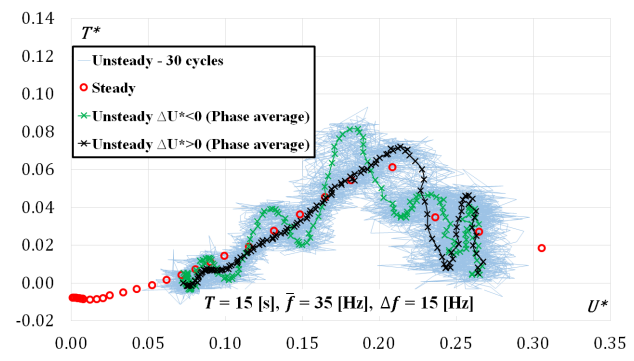

(b)

Figure 6. Torque coefficient, $T^{*}$, vs. flow coefficient, $U^{*}$, in absence of flow separation (test at $T=15 \mathrm{~s}, \bar{f}=20 \mathrm{~Hz}, \Delta f=15 \mathrm{~Hz}$ ) (a); and in presence of flow separation (test at $T=15 \mathrm{~s}$, $\bar{f}=35 \mathrm{~Hz}, \Delta f=15 \mathrm{~Hz})(\mathrm{b})$.

Figure $6 \mathrm{~b}$ describes instead the typical behaviour of the machine under dynamic stall conditions with large oscillations of the mass flow rate. In this case, only the mean frequency value, $\bar{f}$, has been increased in the frequency signal of the vector control $(T=15 s, \bar{f}=35 \mathrm{~Hz}$ and $\Delta f=15 \mathrm{~Hz}$ ). This means that the turbine works in a more stressful condition with higher $\bar{f}$, which involves greater $U^{*}$ (i.e. greater flow rates). Under this flow conditions, a clockwise hysteretic loop appears due to flow separation. Indeed, $T^{*}$ increases during the flow acceleration until the stall occurs with an abrupt drop in the $T^{*}$. However, significant damped fluctuations appear, which continue during the flow deceleration (green line), delaying the flow reattachment, as already showed in a previous work [10]. Those fluctuations are caused by the release of vortices from the leading edge, which grow, detach and travel over the blade suction side, as evidenced by McCroskey [16]. The same phenomenon has been shown to occur during dynamic stall of a pitching airfoil [17].

In order to better understand the influence of the frequency amplitude, $\Delta f$, three tests have been compared. The three tests are characterized by a frequency signal with the same period, $T=15 s$, and the same mean value, $\bar{f}=35 \mathrm{~Hz}$, but different frequency amplitude, $\Delta f,(5$, 10 and $15 \mathrm{~Hz}$, respectively). In the specific, Figures $7 \mathrm{a}, 7 \mathrm{~b}$ and $7 \mathrm{c}$ report the comparison between the $T^{*}$, acquired over 30 cycles, and the corresponding phase-averaged values for each test.

In Figures $7 \mathrm{a}, T^{*}$ follows a regular sinusoidal behaviour, indicating that the frequency amplitude is not large enough to induce the turbine to work under dynamic stall conditions differently from what happens in Figures $7 \mathrm{~b}$ and $7 \mathrm{c}$. Indeed, in these last two cases, it is possible to notice the initial smooth increase of $T^{*}$ and then, after stall occurs, the appearance of torque fluctuations. In both cases, a red dot indicates the stall condition corresponding to a $U^{*}=0.21$. Moreover, it is worth to notice how the number of fluctuations increases from Figure $7 \mathrm{~b}$ to Figure $7 \mathrm{c}$. Since the period is kept constant, when the frequency amplitude of the vector control drive increases, the flow rate amplitude increases, and this means that the angle of attack changes more rapidly. This causes the detached leading-edge vortices to travel faster over the blade suction side, increasing the number of torque fluctuations.

It is reasonable to suspect that those fluctuations can be caused by the fluctuations of either the mass flow rate or the pressure drop. However, looking at Figures 8 and 9, it is evident that neither the stagnation pressure drop coefficient, $\Delta p^{*}$, nor the mass flow rate, $G$, 


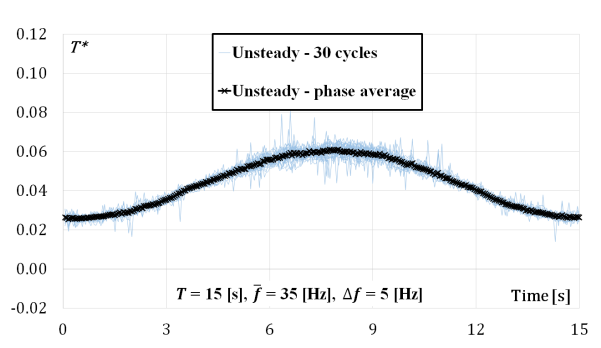

(a)

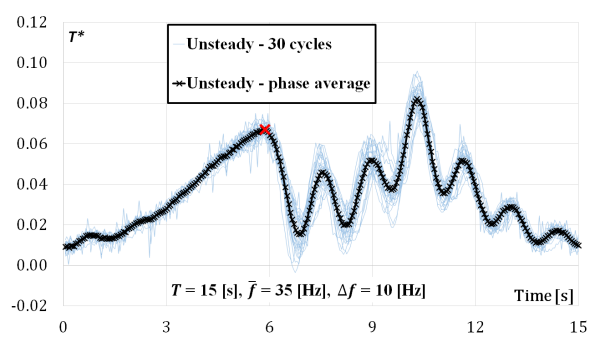

(b)

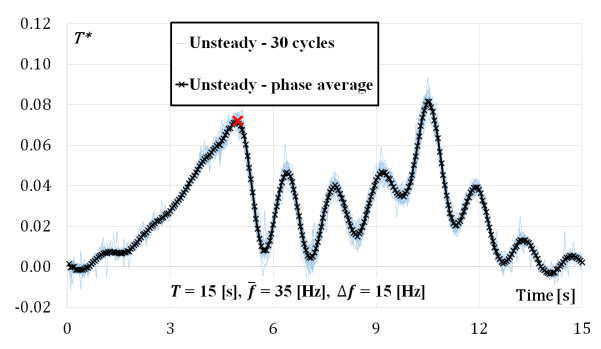

(c)

Figure 7. Influence of the frequency amplitude, $\Delta f$, on phase averaged torque coefficient, $T^{*}$.

show any significant fluctuation in their phase averaged curves, which means that cannot be the cause of the $T^{*}$ fluctuations.

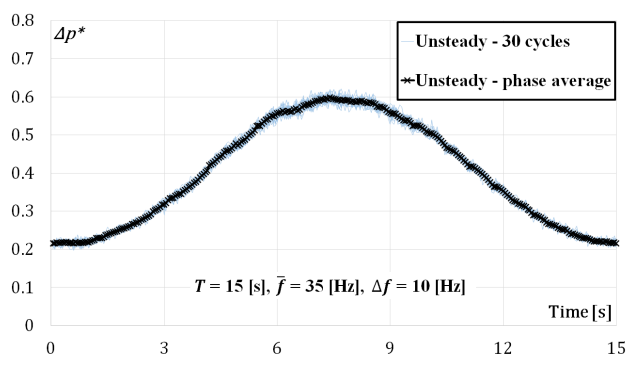

(a)

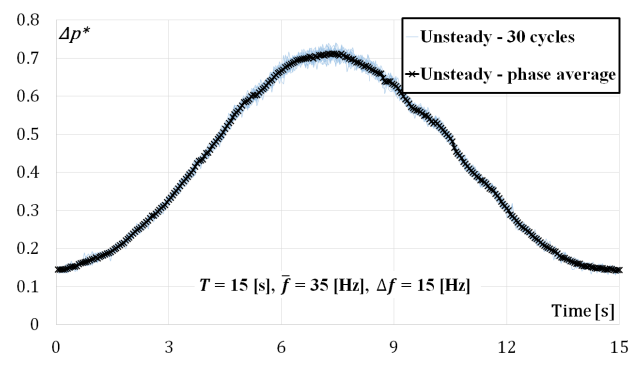

(b)

Figure 8. Stagnation pressure drop coefficient, $\Delta p^{*}$ acquired over 30 cycles, in absence of flow separation (a); and stagnation pressure drop coefficient, $\Delta p^{*}$ acquired over 30 cycles, in presence of flow separation (b).

Figure 10 depicts the comparison between unsteady $T^{*}$ curves obtained by keeping constant $\bar{f}$ and $\Delta f$, but changing the period of the frequency signal of the vector control drive in order to focus on the influence of this parameter on the cycle. Indeed, it is possible to note that $T^{*}$ shows greater fluctuations in the decelerating phase $\left(\Delta U^{*}<0\right)$, as the period decreases. Moreover, keeping constant $T$ and $\bar{f}$, the amplitude of the $T^{*}$ fluctuations become more pronounced as $\Delta f$ increases, i.e. as the turbine works with greater flow rates. 


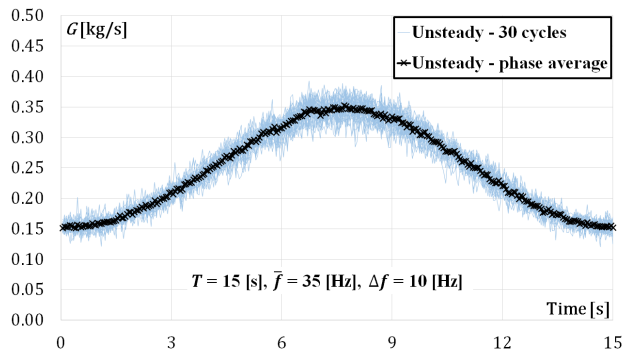

(a)

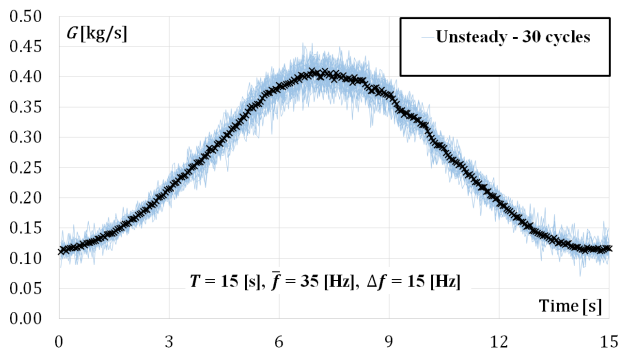

(b)

Figure 9. Phase averaged mass flow rate, $G$, acquired over 30 cycles, in absence of flow separation (a); phase averaged mass flow rate, $G$, acquired over 30 cycles, in presence of flow separation (b).

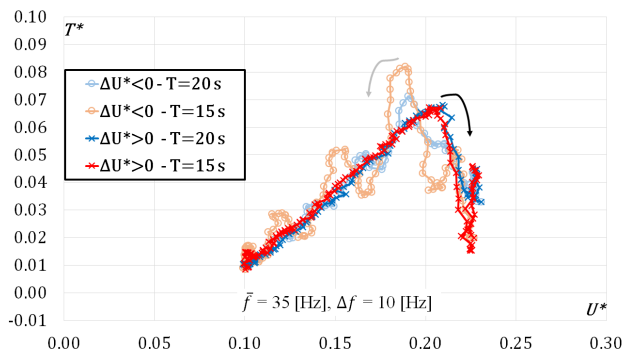

(a)

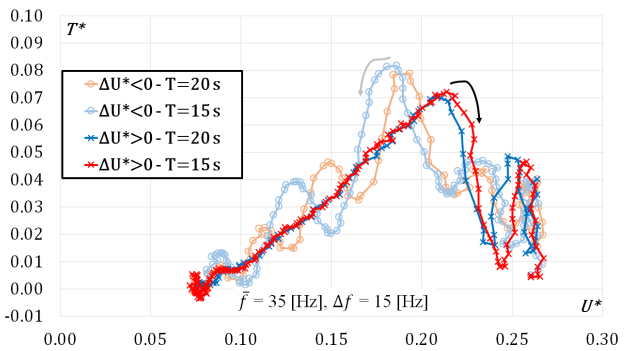

(b)

Figure 10. Torque coefficient, $T^{*}$, vs. flow coefficient, $U^{*}$, in presence of flow separation at different periods $T$ (tests at $\bar{f}=35 \mathrm{~Hz}, \Delta f=10 \mathrm{~Hz}$ ) (a); Torque coefficient, $T^{*}$, vs. flow coefficient, $U^{*}$, in presence of flow separation at different periods $\mathrm{T}$ (tests at $\bar{f}=35 \mathrm{~Hz}$, $\Delta f=15 \mathrm{~Hz})(\mathrm{b})$.

\section{Conclusions}

In conclusion, in this work a Wells turbine, designed and manufactured by means of a 3D printer, has been investigated in the GaVe-PrInCE laboratory of the Polytechnic University of Bari in order to focus on its performance under unsteady flow conditions. The unsteady flow conditions have been obtained by creating an unidirectional sinusoidal oscillating flow. In this way, it has been possible to investigate how the hysteresis cycle changes during both the design working conditions and when the stall phenomenon occurs. A series of tests have been carried out by changing and combining the three main parameters, which describes the oscillating flow, i.e. the period, the mean frequency and the amplitude of the frequency signal of the vector control drive.

During unsteady tests, the Wells turbine can work either in absence or in presence of flow separation. In the case of flow separation, its performance shows a hysteretic behaviour due to dynamic stall phenomenon, especially when high flow rates are reached. Furthermore, when dynamic stall occurs, the shaft torque registers, during the flow reduction and the flow reattachment, damped fluctuations at frequencies higher than that of the main flow. In addition, these fluctuations intensify as the amplitude increases and the wave period decreases.

Moreover, the experimental campaign has showed that both the stagnation pressure drop coefficient, $\Delta p^{*}$, and mass flow rate, $G$, do not show fluctuations in their phase averaged curves, which means that they cannot be the cause of the $T^{*}$ fluctuations. It is believed that 
these are are due to the release of vortices from the leading edge, which grow, detach and travel over the blade suction side.

The authors gratefully acknowledge Giovanni Bellino, Nicola Favia and Paolo Fragasso for their help during the experimental activities.

\section{References}

[1] IRENA, Global Renewable Outlook: Energy Transformation 2050 (International Renewable Energy Agency, 2020).

[2] G. Mørk, S. Barstow, A. Kabuth, M. Pontes, “Assessing the Global Wave Energy Potential" in Proceedings of the 29th International Conference on Ocean, Offshore and Arctic Engineering, 3 (ASME, 2010), pp. 447-454.

[3] IRENA, https://www.irena.org/ocean.

[4] A. M. Cornett, "A Global Wave Energy Resource Assessment" in Proceedings of the 18th International Offshore and Polar Engineering Conference, (2008).

[5] I. López, J. Andreu, S. Ceballos, I. Martinez de Alegria, I. Kortabarria, Renewable and Sustainable Energy Reviews 27, (2013).

[6] S. Raghunathan, Prog. Aerospace Sci. 31, (1995).

[7] T. Ghisu, P. Puddu, F. Cambuli, Journal of Thermal Science 24, (2015).

[8] J. C. C. Henriques, L. M. C. Gato, Computational Mechanics 29, (2002).

[9] M. Torresi, S. M. Camporeale, G. Pascazio, Journal of Fluids Engineering 131 (7), (2009).

[10] M. Torresi, M. Stefanizzi, F. Fornarelli, L. Gurnari, P.G.F. Filianoti, S.M. Camporeale, "Performance characterization of a wells turbine under unsteady flow conditions" in Proceedings of the 74th Conference of the Italian Thermal Machines Engineering Association, AIP Conference Proceedings 2191 (2019), 020149.

[11] M. Torresi, S. M. Camporeale, G. Pascazio, "Performance of a small prototype of a high solidity wells turbine" in Proceedings of the $7^{\text {th }}$ European Conference on Turbomachinery: Fluid Dynamics and Thermodynamics (ETC, 2007).

[12] M. Torresi, S. M. Camporeale, G. Pascazio, "Experimental and numerical investigation on the performance of a Wells turbine prototype" in Proceedings of the 7th European Wave and Tidal Energy Conference (2007).

[13] M. Torresi, S. M. Camporeale, G. Pascazio, Renewable Energy 33, (2008).

[14] T. Ghisu, P. Puddu, F. Cambuli, I. Virdis, "On the Hysteretic Behaviour of Wells Turbines" in Proceedings of the 72nd Conference of the Italian Thermal Machines Engineering Association, Energy Procedia 126 (Elsevier, 2017), pp. 706-713.

[15] I. Virdis, T. Ghisu, F. Cambuli, P. Puddu, Energy Procedia 148 (2018), pp. 503-510.

[16] W.J. McCroskey, "The phenomenon of dynamic stall”, Tech. Rep., Natl. Aeronaut. Space Admin., Washington, DC, 1981.

[17] Torresi M, De Tomaso E, Fortunato B, Camporeale SM. "High frequency dynamics of force coefficients in VAWT blades under dynamic stall condition" in Proceedings of ASME Turbo Expo 2015: Power for Land, Sea and Air, (2015), GT2015-42987. 